\title{
Experimental and Numerical Evidence of the Clustering Effect of Structures on Their Response during an Earthquake: A Case Study of Three Identical Towers in the City of Grenoble, France
}

\author{
by Philippe Guéguen and Andrea Colombi
}

\begin{abstract}
In this article, interpretation of an equivalent to a macroseismic intensity survey, performed in three identical stand-alone buildings located in Grenoble, France, after an $M_{\mathrm{L}} 4.1$ earthquake, reveals a clustering effect, resulting in different levels of perception of seismic loading by inhabitants. The clustering effect is confirmed using numerical simulation; the variation of the seismic response of the building in the middle of the cluster depends on the azimuth of the seismic source relative to the building cluster. The major effect is the splitting of its resonance frequency, accompanied by a decrease in vibration amplitude. We conclude that clustering has an impact on urban effects, calling into question the validity of seismic design, which considers buildings in urban areas as stand-alone constructions, and the interpretation of macroseismic intensity surveys conducted in dense urban areas.
\end{abstract}

\section{Introduction}

On the scale of the city, seismic risk analysis requires assessment of seismic ground motion, including site effects, and of structural response. These ingredients are essential to implement management strategies and to reduce human and economic losses. These two elements are often analyzed independently; that is, ground motion is analyzed without including the urban elements (structures and infrastructures) as secondary sources contaminating the seismic input motion, and the structures are considered as stand-alone constructions, ignoring possible interactions with their urban environment.

Nonetheless, it has long been known that surface heterogeneities can significantly alter incident wavefields by amplifying the seismic ground motion in the presence of site effects or by modifying the boundary conditions of the system. For example, the impedance contrast between soil and foundation is at the origin of the kinematic soil-structure interaction (KSSI; Kausel, 2010). The interaction introduces scattering and resonant phenomena over the length of the foundations (Stewart and Fenves, 1998) that can pollute the incident wavefield. In such cases, KSSI modifies the response of neighboring buildings (Wong and Trifunac, 1975). This effect is exacerbated in the presence of a strong impedance contrast between the soil and the foundations. On the other hand, Jennings (1970), Kanamori et al. (1991), Guéguen et al. (2000), Cornou et al. (2004), and Kim et al. (2001) identified waves in seismic ground motions recorded in urban areas or close to buildings. These waves are generated by structure vibrations, due to inertial soil-structure interaction (ISSI). ISSI generates waves that are diffracted back into the ground and superimposed upon the seismic input ground motion. For the aforementioned observations, the structures were excited by internal or external forces applied at the top, and the wave diffracted into the soil was easily identifiable on the recording stations. This is not a local phenomenon, because Kanamori et al. (1991), Favela et al. (2002), and Kim et al. (2001) have observed ISSI at distances of over $50 \mathrm{~km}$. These observations have been confirmed by simplified 2D numerical modeling (Wirgin and Bard, 1996) and generalized to a building cluster simulating a city (Kham et al., 2006, Isbiliroglu et al., 2015), reproducing, in some cases, the unusually long and monochromatic waves observed in Mexico City in 1985 (Singh et al., 1988).

This effect is not negligible and raises the question of how the response of the sedimentary sites and structures can be polluted by the redistribution of seismic energy on the surface of the city. In Japan, in 1935, Sezawa and Kanai (1935) noticed that attenuation of the earthquake effects over distance seemed more important at the outskirts of towns, and they attributed this observation to local coupling between the city and the soil. Guéguen et al. (2002) simulated the contribution of the Roma Norte district of Mexico City to the total seismic ground motion. They showed that site effects evaluated using the standard site-to-reference spectral ratio method cannot be explained without taking account of the urban layer. They called this phenomenon site-city interaction. Kitada et al. (1999) also showed experimentally that for two close structures, structure-soil-structure interaction changed the dynamic response of the structures themselves, particularly by splitting their fundamental frequency, that is, generating monochromatic beats in the time-domain 
(a)

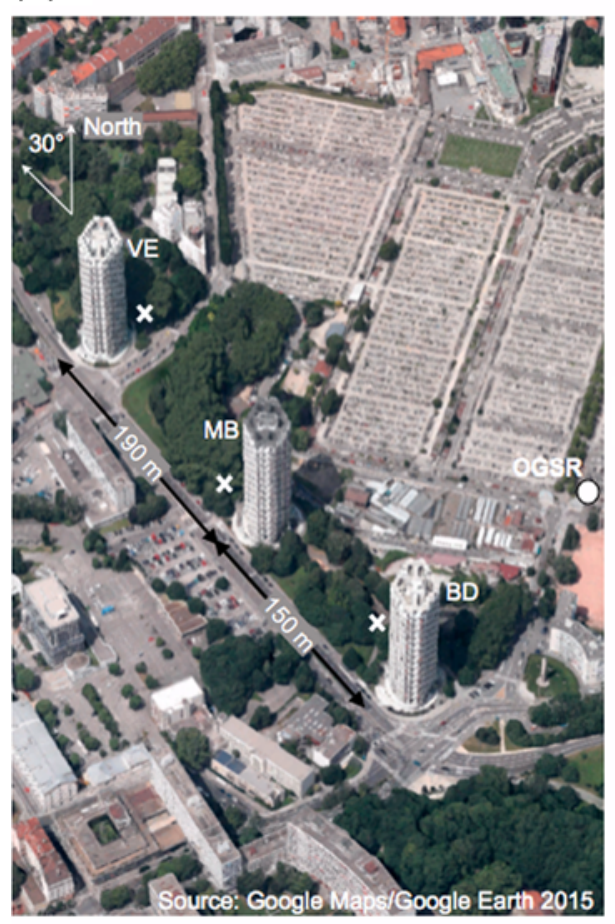

(b)

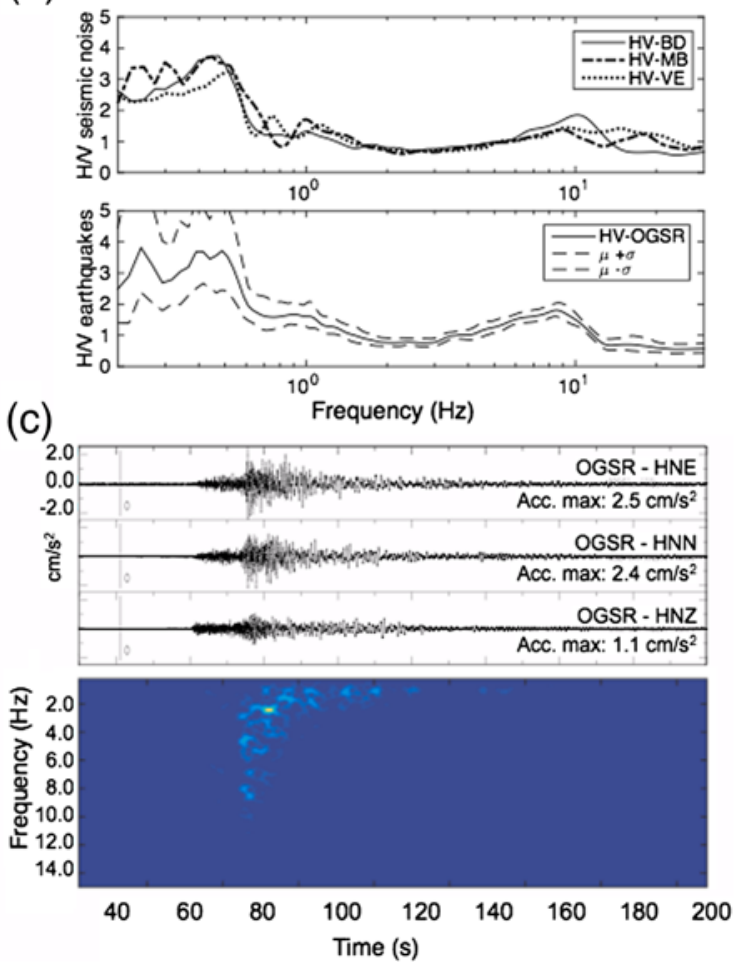

Figure 1. (a) Position of the building cluster in Grenoble's city. BD, MB, and VE are the Belledonne, Mont-Blanc, and Vercors towers, respectively. OGSR is the permanent accelerometric station from the French Accelerometric Network (Péquegnat et al., 2008). White crosses show the position of the horizontal-to-vertical (H/V) spectral ratio computed using ambient vibration. (b) Mean value of the H/V spectral ratio using ambient vibrations (upper row) computed at the bottom of the $\mathrm{BD}, \mathrm{MB}$ and $\mathrm{VE}$ towers in the free field (processing as described in Guéguen et al., 2007), and mean value of the $\mathrm{H} / \mathrm{V}$ spectral ratio using earthquake data (lower row) recorded at OGSR since its operation ( \pm standard deviation). (c) Time histories of acceleration recorded at the OGSR station during the $2014 M_{\mathrm{L}} 5.1$ earthquake in the east (HNE), north (HNN), and vertical (HNZ) directions and the time-frequency distribution of the HNE component. Maximal acceleration is indicated on the right side of the figure. The color version of this figure is available only in the electronic edition.

structure response. This observation has been confirmed by centrifuge tests and numerical modeling (Bard et al., 2008), and by numerical modeling applied to a building pair during the 2002 Molise earthquake (Laurenzano et al., 2010). At the scale of a city composed of a multitude of resonant structures, it is easy to imagine strong coupling between the multiple structures and the soil, redistributing the incident seismic energy. This raises questions concerning the validity of seismic ground-motion assessments in urban areas, the understanding and interpretation of site effects observed during earthquakes, and the design capacity of structures if urban environment effects are ignored. This group effect has already been described in physics through the concept of metamaterials (e.g., Colombi et al., 2014). Applied to geophysics, these metamaterials cause a redistribution of seismic wave energy, such as forbidden frequency bands, for example, or bandgaps (Brûlé et al., 2014; Nicoletti, 2014; Colombi et al., 2016).

The purpose of this article is to analyze an observation reported in Grenoble, France, during an earthquake, interpreted as being the consequence of the dynamic coupling within a building cluster.

\section{Observation of the Coupling in Grenoble}

The genesis of this article comes from an observation made on three identical towers located in Grenoble, France, during an earthquake (Fig. 1). In 2014, an $M_{\mathrm{L}} 4.9$ earthquake occurred $100 \mathrm{~km}$ south of Grenoble in the swarm region of Ubaye (Courboulex et al., 2013; Courboulex et al., 2014). An accelerometric station (OGSR) of the permanent French Accelerometric Network (Péquegnat et al., 2008) located in the vicinity of the towers (Fig. 1a) recorded weak horizontal peak ground acceleration of $2.5 \mathrm{~cm} / \mathrm{s}^{2}$. The $Y$-shaped sedimentary basin of the Grenoble valley, composed of thick (up to $1 \mathrm{~km}$ ), soft glacio-lacustrine deposits, generating major low-frequency site effects, is well known in Grenoble (Lebrun et al., 2001; Guéguen et al., 2007). Seismic ground motion is systematically amplified throughout the basin, between 0.3 and $5.0 \mathrm{~Hz}$ by a factor of 5 to 10 , as a consequence of the 3D effects of the valley (Cornou and Bard, 2003). People in Grenoble's tall buildings always feel earthquakes significantly. This was particularly the case during the 2014 earthquake for the inhabitants of the three towers. These residential buildings located in the center of the basin and consisting of 29 floors are perfectly identical in shape and 
design. They are $98 \mathrm{~m}$ tall, $60 \mathrm{~m}$ long, and $43 \mathrm{~m}$ wide, and the center-to-center distance is approximately $100 \mathrm{~m}$. They are aligned in a $\mathrm{N} 30^{\circ} \mathrm{W}$ direction at an angle of $\mathrm{N} 0^{\circ}$, with the Vercors (VE) and Belledonne (BD) towers located at either end and the MontBlanc (MB) tower in the middle. The foundations are identical: shallow foundations embedded on two basements $(H=6 \mathrm{~m})$, anchored on a stiff sand and gravel layer present at $6 \mathrm{~m}$ deep, corresponding to the fluviatile deposits present almost everywhere in the Grenoble basin. Site response was computed using the conventional horizontalto-vertical (H/V) spectral ratio using ambient noise, recorded on the ground at the bottom of the towers, and the $\mathrm{H} / \mathrm{V}$ spectral ratio using earthquake data recorded at OGSR (see Guéguen et al., 2007, for description of the processing). We observe a very homogenous site response in the area covered by the towers (Fig. 1b). Amplification at $0.4-0.5 \mathrm{~Hz}$ was observed, corresponding to the deep basin response (Guéguen et al., 2007). A second amplification was observed at about $8-10 \mathrm{~Hz}$, corresponding to the response of the uppermost sediment overlaying the stiff sandy-gravel layer. The overlying layer consists of soft clay materials $\left(V_{S}\right.$ of about $200 \mathrm{~m} / \mathrm{s}$ ), giving peak amplification at $8.3 \mathrm{~Hz}$, according to the conventional 1D relationship for site amplification $\left(f=V_{S} / 4 H\right)$. We also observe (Fig. 1c) that maximum seismic energy is concentrated between 1 and $8 \mathrm{~Hz}$, with the maximum at $2 \mathrm{~Hz}$, corresponding to the arrival time (80 s) of the $S$ waves.

Immediately after the earthquake, a local survey, based on the protocol used for macroseismic intensity analysis (Grünthal, 2011), was conducted among the inhabitants of the three towers. This microseismic survey (by analogy with macroseismic surveys) was similar to the "Did You Feel It?" form of most seismological surveys (Atkinson and Wald, 2007; Sbarra et al., 2010; Wald et al., 2012). We used the iconographic representation originally proposed by the French Central Bureau for Seismology (BCSF) of Strasbourg University and shown on the SismoCom mobile tool for how the quake was felt (Sira et al., 2010). Several images representing the severity of the shaking, according to the observations and perceptions of inhabitants, are proposed to classify the level of vibration in the structures. No damage was observed, and only the images corresponding to the first four levels of intensity were distributed to inhabitants, who were asked to select the image that best represented what they felt and to indicate their location in the building at the time of the earthquake. In total, 126 people responded, that is, 41,36 , and 49 for towers $\mathrm{MB}, \mathrm{BD}$, and VE, respectively. The representation of the microseismic intensities in each tower is shown in Figure 2a. Except for a few cases, at least one questionnaire per floor was returned, and some inhabitants answered that they did not feel the shaking. The quality of the results of such surveys depends on their completeness and bias, because response is spontaneous (Mak and Schorlemmer, 2016); this quality is not discussed herein. The microseismic intensity survey ranged from grades 0 to 4 , corresponding to not felt, slight, weak, moderate, and significant feeling. For each floor (Fig. 2a), the mean value of the responses collected in the towers was computed and ranged from 0 to 3. The earthquake was felt more on the intermediate floors, between 10 and 20, where the highest perceived intensities were concentrated. Second, starting from the premise that the perceptions of the inhabitants are directly related to the amplitude of the vibration, we assume larger vibrations in the $\mathrm{BD}$ and VE buildings, located at the ends of the cluster. The highest intensities are of the order of 2 , with some reaching 3 . In MB, the amplitude was lower, reaching only intensity 1 .

These towers have been the subject of numerous studies for several years. In particular, ambient vibration-based methods have been applied to the towers to evaluate their modal response (Mikael et al., 2013; Valla et al., 2014). Two approaches have been applied, the first consisting in computing the Fourier spectrum of ambient vibrations recorded at the top of the building in the transverse (T) and longitudinal (L) directions; the second by applying frequency domain decomposition (FDD, Brincker et al., 2001) with ambient vibrations recorded on 15 different floors in MB to identify the modal shapes linked to each modal frequency. The experimental protocol is described in Michel et al. (2010): a Cityshark II acquisition system and six Lennartz 3D $5 \mathrm{~s}$ velocimeters were used, keeping a reference sensor at the top of the building. Several sets of 15-min-long recordings (200 samples per second) were made, moving the velocimeters along the height of the building. The singular value decomposition used for FDD was then obtained by merging all the sets after normalization based on the top recording. Fourier transforms of ambient vibrations recorded at the top of the buildings using a single station and the resulting mode shapes analysis by FDD applied to the MB tower are displayed in Figure $2 b$ and $2 c$, respectively. The thin dashed vertical lines show the resonance frequencies observed in the three towers. At first glance, we observe that the VE and BD towers have the same resonance frequencies compared to the MB tower. For the MB tower, the first two horizontal modes (Fig. 2b) were 0.65 (label 1), $2.55 \mathrm{~Hz}$ (label 4) and 0.84 (label 2), $2.54 \mathrm{~Hz}$ (label 4) in the east-west and north-south directions, respectively. An additional torsion mode at $0.96 \mathrm{~Hz}$ (label 3) was also observed in $\mathrm{MB}$, and a second horizontal harmonic mode at $5.8 \mathrm{~Hz}$ (north-south) and $5.5 \mathrm{~Hz}$ (east-west) is also reported in Figure $2 \mathrm{~b}$. The three resonance frequencies correspond to horizontal bending modes, with mode shapes corresponding to the bending model (Fig. 2c). Mode shapes were extracted by FDD, and we observe that the second mode, corresponding to $2.5 \mathrm{~Hz}$, has a node located on the fourteenth floor, with maximum amplitude between the tenth and twelfth floors. Similar mode shapes were obtained by Valla et al. (2014) for the VE and BD towers, using ambient vibration-based methods, confirming the similarity in design of the three towers. However, some variations in frequency values are observed because of unavoidable imperfections and variations in design or construction when the three towers were built: 0.68 (label 1) and 
(a)

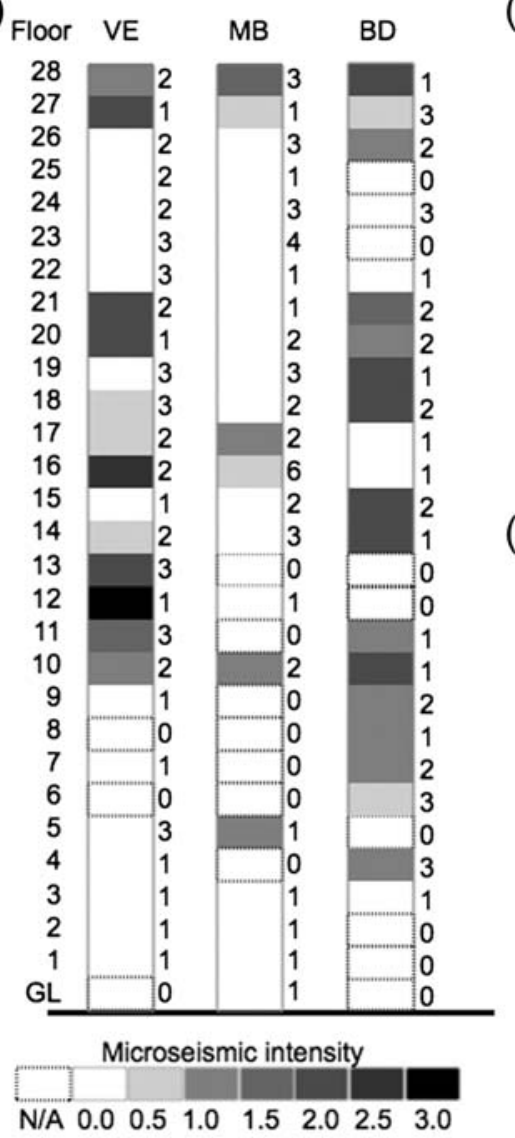

(b)

(c)
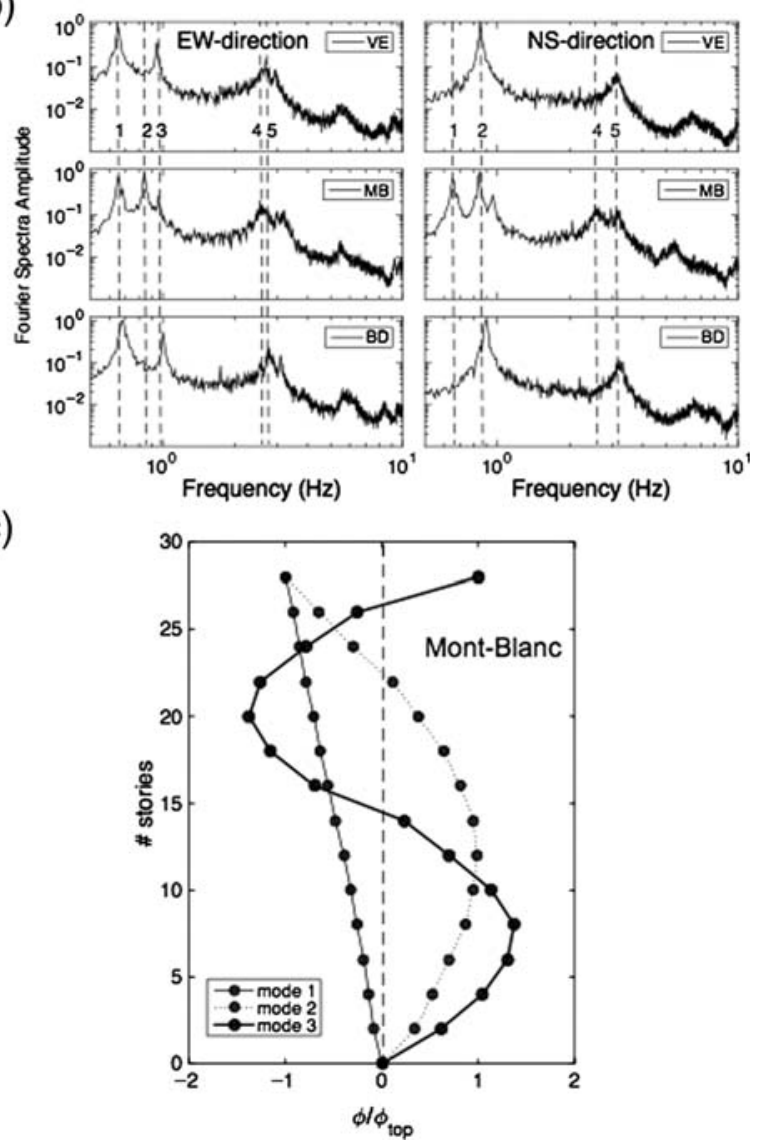

Figure 2. (a) Results from the microseismic intensity survey performed in the three towers (N/A: not available data). Numbers to the right of each tower indicate the number of questionnaires collected per floor. (b) Normalized Fourier spectra amplitude of ambient vibrations recorded at the top of the buildings in the longitudinal (north-south) and transverse (east-west) directions. Thin dashed vertical lines show the positions of the modes discussed in the article. (c) Shapes of the three first modes of the MB tower obtained using operative modal analysis methods based on ambient vibrations (frequency domain decomposition, Brincker et al., 2001), normalized by the top amplitude.

$2.73 \mathrm{~Hz}$ (label 4) in the east-west direction, 0.90 (label 2) and $3.21 \mathrm{~Hz}$ (label 5) in the north-south direction, and $1.0 \mathrm{~Hz}$ (label 3) in torsion for BD; 0.65 (label 1) and $2.67 \mathrm{~Hz}$ (label 4) in the east-west direction, 0.85 (label 2) and $3.19 \mathrm{~Hz}$ (label 5) in the north-south direction, and $0.95 \mathrm{~Hz}$ (label 3) in torsion for VE. As for the microseismic study, the dynamic response of MB differs from the responses of the other two towers, with significant coupling of the two horizontal modes, a less acute torsion mode and a shift of the second horizontal mode (label 4) toward the lowest frequencies in the north-south direction.

For the inhabitants of VE and BD, the largest amplitude of vibration was felt between the tenth and twentieth floors, corresponding to the node of the second horizontal mode shape. As aforementioned, the largest amplitude of the seismic ground motion recorded by the closest station is centered on $2 \mathrm{~Hz}$ (Fig. 1c), close to the frequency of the second mode. We can assume exacerbated excitation for this mode due to resonance effects between the input seismic ground motion with the building response, without direct contribution of the site effects at this frequency, and comparable to the outcome of the microseismic survey. Several reasons can be proposed to explain the differences observed in the dynamic response and the microseismic survey between MB, VE, and BD. Unexpected differences in the design and variations of ageing effects between towers may be part of the explanation. However, it is interesting that this difference appears in the middle tower, that is, where the only noticeable difference is its surrounding urban environment. Being inserted between the other two towers, BD and VE, may affect MB and, as shown by Kitada et al. (1999) and Bard et al. (2008), could alter its spectral response. Without the 2014 earthquake recordings in the three towers, this coupling, also observed in the microseismic survey, cannot be confirmed. We will therefore use numerical modeling techniques to try to confirm the structure-soil-structure interaction that may exist.

\section{Numerical Modeling}

Numerical simulations are computed with SPECFEM3D (Peter et al., 2011). The viscoelastic wave equation is time integrated on the model using a high-order spectral element 


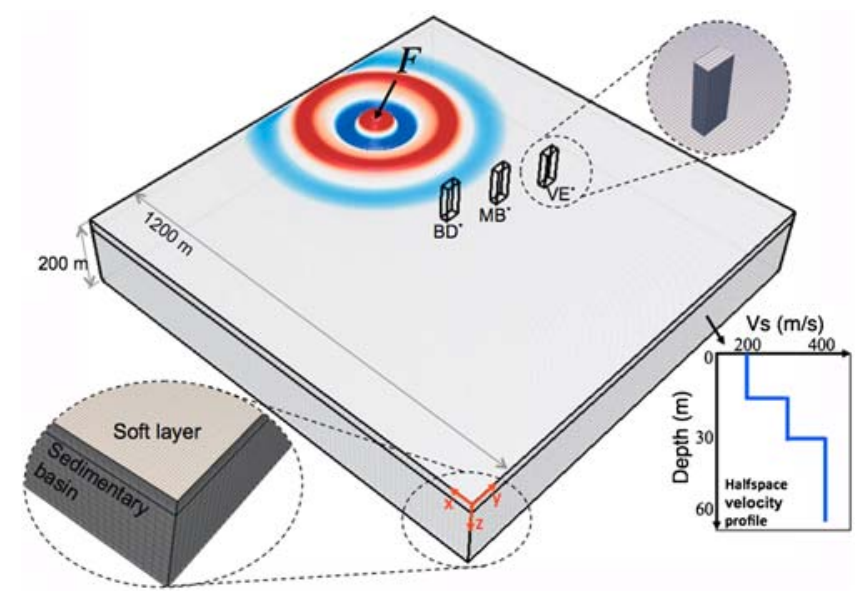

Figure 3. Numerical model of the elastic half-space and the three towers used in the simulations. The velocity model of the halfspace as well as the meshing strategy are highlighted in the insets. The source is located on the west side with respect to the building cluster. The superscript $*$ means numerical buildings. The color version of this figure is available only in the electronic edition.

method in space and a second-order time-difference scheme. This method has proven to be highly accurate and perfectly scalable on parallel computers and has a long history of success in modeling seismic wave propagation (e.g., Padovani et al., 1994; Fichtner et al., 2009; Peter et al., 2011). In the numerical model, the three towers are located on top of a $1.2 \times 1.2 \mathrm{~km}$ square half-space, $200 \mathrm{~m}$ deep (Fig. 3). The size and spacing of the towers are accurately modeled, respecting the in situ scale dimension. The model is discretized with hexahedra using the CUBIT software package. To enable the inclusion of Love waves in the simulations, as well as Rayleigh and $S H$ waves, a low-velocity layer is introduced in the subsurface. Thus, while the background shear-wave velocity $V_{S}$ in the half-space is set to $400 \mathrm{~m} / \mathrm{s}$, and the quality factor $Q$ is 60 , that is, average values for the Grenoble basin taken from previous studies (e.g., Guéguen et al., 2007), the first $30 \mathrm{~m}$ of the half-space are characterized by the velocity profile depicted in Figure 3. The quality factor in this layer is reduced to 30 , whereas the density $\rho$ is set to $2000 \mathrm{~kg} / \mathrm{m}^{3}$ for the whole half-space.

To simulate the unboundedness of the domain, perfectly matched layers are applied to the side and bottom surfaces of the half-space, whereas the top layer is traction free. Nonlinear coupling between soil and foundations cannot be included, because we are modeling linear elasticity (and attenuation). We can, however, account for the scattering effect produced by the foundations on the wavefield at the surface by inserting a $6 \mathrm{~m}$ deep heterogeneity with $V_{S}=1000 \mathrm{~m} / \mathrm{s}$ beneath each building (same cross section) to represent the deep foundations.

The towers have a rectangular cross section and dimensions respecting in situ scale. The material properties of the towers $\left(\rho=250 \mathrm{~kg} / \mathrm{m}^{3}, V_{P}=1350 \mathrm{~m} / \mathrm{s}\right.$ and $\left.V_{S}=650 \mathrm{~m} / \mathrm{s}\right)$ are calculated to reproduce the first two horizontal fundamental modes (the most relevant to this study). To facilitate meshing, the towers are rotated and aligned with the side of the halfspace that corresponds to the in situ orientation and alignment of the three towers. Given the rectangular cross section, there are slight, though unavoidable differences between the eastwest and north-south responses. The first two modes for the north-south direction, numerically calculated, are 0.75 and $2.65 \mathrm{~Hz}$, whereas for east-west, they are 0.5 and $2.1 \mathrm{~Hz}$. Building damping (Mikael et al., 2013; Valla et al., 2014) translates into a quality factor $Q=10$ corresponding to an equivalent critical damping equal to $5 \%$.

To evaluate the effects of the VE and BD towers on MB, two meshed models were generated. Model 1 only features the stand-alone MB tower and is used to calculate the reference response of the buildings. The three towers are present in model 2 and correspond to the building cluster in Grenoble. Simulations were run in parallel on 64 cores to compute 30-s-long synthetic seismograms. First, we considered a source located to the west of the numerical domain, that is, in a direction perpendicular to the cluster (Fig. 3). The forcing vector is tilted to excite motion along the three orthogonal directions and is driven by a Ricker source time function (amplitude $10^{5} \mathrm{~N}$ ) centered at $2 \mathrm{~Hz}$.

Figure $4 \mathrm{a}$ shows the transfer functions between one point in the center of the top of the tower and one located in the center of the base. Figure $4 \mathrm{~b}$ shows the Fourier spectrum of the building motion calculated in the East direction ( $X$-direction) at the top of the MB tower for models 1 (stand-alone) and 2 (cluster). Transfer functions were calculated using a conventional water-level $(\mathrm{wl}=10 \%)$ deconvolution method (Clayton and Wiggins, 1976). The difference between the transfer function and the Fourier spectrum reflects the difference between the system response (including soil-structure interaction) and the so-called pseudoflexible response of the building, including the rocking motion of the foundation. Numerical resonance frequencies were observed at $0.4 \mathrm{~Hz}$ for the fundamental (first) mode, and at 2 and $5 \mathrm{~Hz}$ for the second and third modes, respectively. These values fit the conventional series of frequency ratios when modeling structures as a continuous Euler-Bernoulli beam, that is, $f_{n} / f_{1}=[(2 n-1) / 1.194]^{2}$, with $f_{1}$ the fundamental resonance frequency and $n$ the higher modes (Clough and Penzien, 2003). The slight reductions in frequency compared with the target numerical values (i.e., 0.5 and $2.1 \mathrm{~Hz}$ in $X$ direction) are due to the SSI effects that exist in the presence of a relatively soft surface layer $\left(V_{S}=200 \mathrm{~m} / \mathrm{s}\right)$. With this configuration, there is no evidence of significant differences in the MB transfer function in amplitude or frequency between the stand-alone and cluster models. This is not the case for the Fourier spectrum (Fig. 4b), which shows the effect of clustering, amplifying the top motion in MB. This results in lengthening of the time history of displacement, and the displacement calculated at the top of MB in the east direction ( $X$-direction) shows monochromatic beats (Fig. 4c). This time particularity is the typical signature of coupling between systems with close frequencies, as already reported in a similar 
(a)
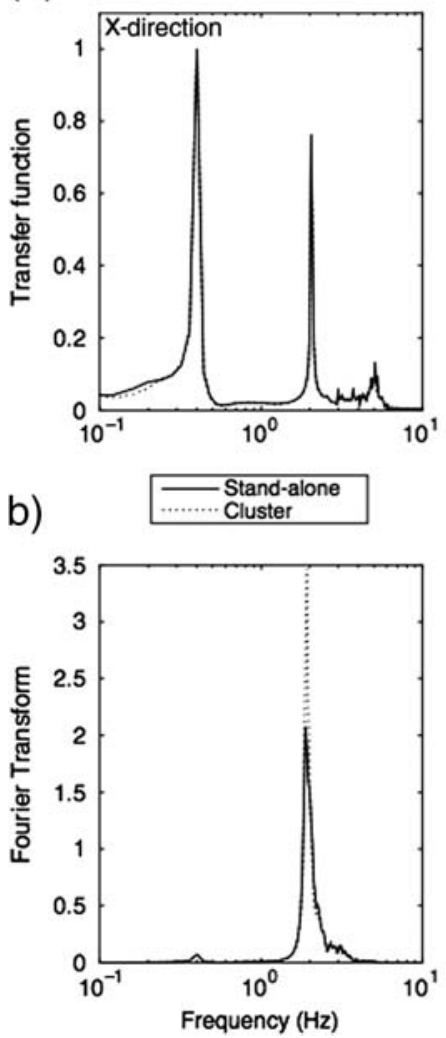

(c)
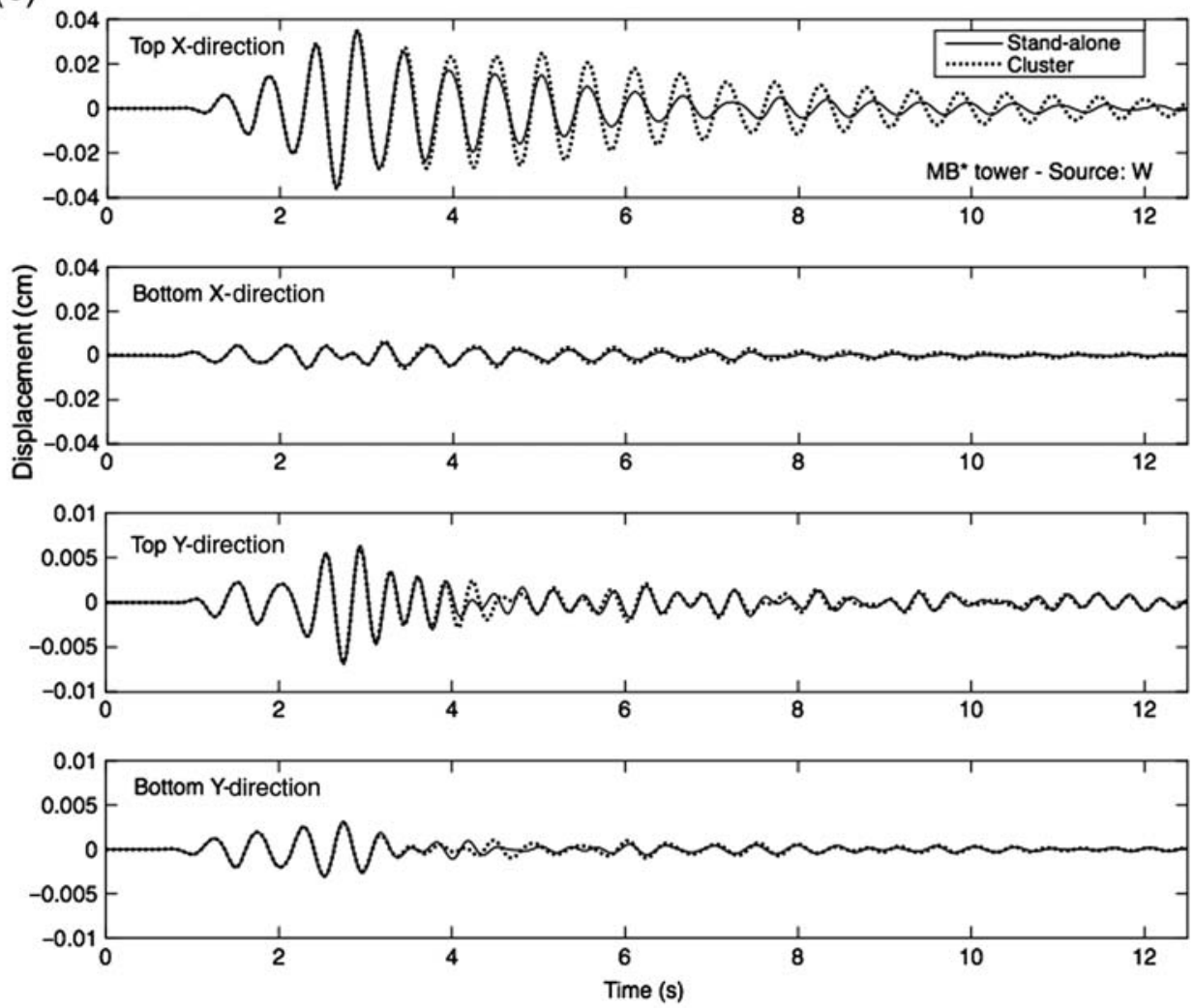

Figure 4. (a) Transfer function and (b) Fourier transforms of the displacement computed at the top of the MB tower in the east-west ( $X$-direction) direction, for a source located to the west, based on the stand-alone (continuous line) and cluster (dotted line) models. (c) Displacement time history computed at the top and the bottom of the MB tower in $X$-direction and $Y$-direction, based on the stand-alone (continuous line) and cluster (dotted line) models, for a source to the west. The superscript $*$ means numerical buildings.

situation, that is, a building forced into vibration (Guéguen et al., 2000). This effect is not present in the north direction ( $Y$-direction), although a change in the oscillation phase is visible between models 1 and 2 at $4 \mathrm{~s}$ (Fig. 4c). This disturbance comes from the interferences at the ground level in the presence of the cluster (Fig. 4c), that is, kinematic interaction effect in the cluster. Kinematic interaction effects are especially significant in the presence of rigid structures and in structures with wide, deeply embedded foundations. The foundation motion is often described by foundation-input motion, a theoretical concept considering massless foundations and structures (Kausel, 2010). In our real case, the cluster effect changes the motion calculated at the foundation level, which results from the cluster interaction, including kinematics and inertial interaction. This effect is less present in the $X$-direction, even though a slight phase shift is observed after approximately $6 \mathrm{~s}$ between the motion computed for models 1 and 2 .

Figure 5a shows the displacement calculated along the height of the three towers for a source located in the west. The maximum displacement of the resulting $X$-direction and $Y$-direction motion, that is, $\left(U_{X}^{2}+U_{Y}^{2}\right)^{1 / 2}$ is shown. Despite totally identical structures, a significant difference is observed between the tower in the middle (MB) and the towers at the two ends of the cluster (VE and BD). The three towers show the largest displacement at the top and between floors 8 and 17 (centered on 11), corresponding to the position of the antinode of the experimental shape of the second mode (Fig. 2c). This result is similar to the findings of the microseismic survey, that is, the absence of vibrations felt by inhabitants (Fig. 2a) on floors 22-24. However, a relevant difference is shown in the MB tower, characterized by lengthening of the displacement time history and the beats described above. It is observed at the top and between floors 8 and 17. As consequences, beats and lengthening can produce stronger vibrations of the MB tower, that is, felt more by inhabitants that does not correspond to the results from the microseismic survey during the 2014 earthquake. However, this earthquake, located to the south of Grenoble, did not have the same azimuth as the numerical experiment, because the waves entered the Grenoble basin south of the cluster and spread laterally between the northern and southern edges of the sedimentary basin. This phenomenon is related to complex 3D geometry and has been described by Cornou and Bard (2003) based on experiments performed by network analysis.

Figure $5 \mathrm{~b}$, therefore, shows the case of a source located to the south of the cluster. Significant differences appear in the response of the three towers, with maximum displace- 
(a)
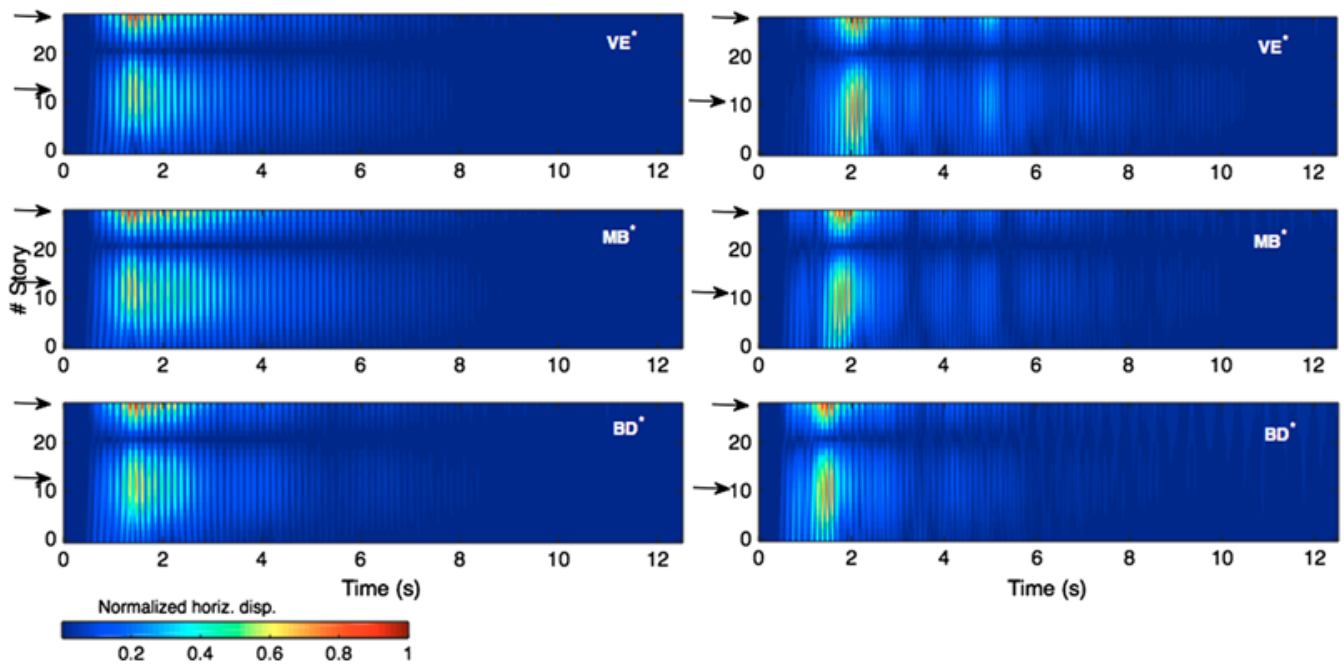

(b)
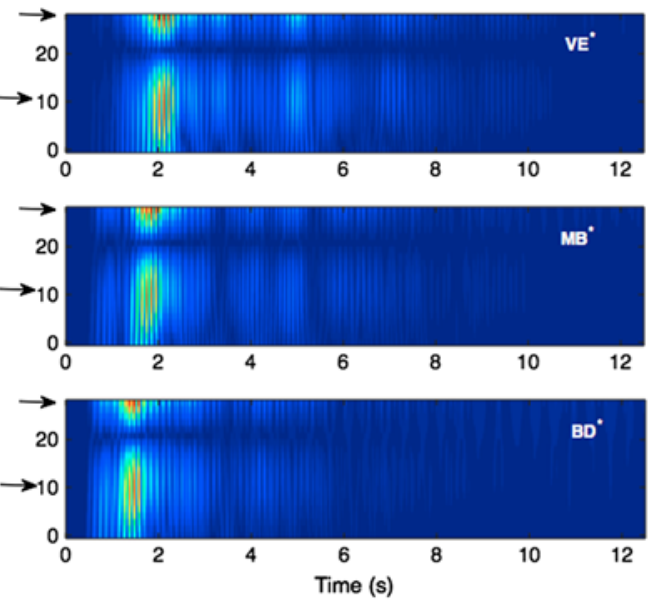

Figure 5. Time histories of the maximum resulting displacement computed along the height of the three numerical clustered buildings (noted *), normalized by the top displacement, and based on (a) the west and (b) the south positions of the source. Arrows indicate the position of the maximum amplitude along the buildings and discussed in the article. The color version of this figure is available only in the electronic edition.

ment being more restricted in time and the beats being less clear. A slight modification in amplitude is also observed between floors 8 and 17 . On these floors, maximum displacement is $86 \%, 75 \%$, and $85 \%$ of top motion for towers VE, $\mathrm{MB}$, and $\mathrm{BD}$, respectively. The decrease in motion for $\mathrm{MB}$ was also reported by the microseismic survey on the 2014 earthquake, for which the source was in the south, and in the presence of the building cluster.

\section{Discussions and Conclusions}

Kitada et al. (1999) studied how the frequency response of a stand-alone structure can be modified by changing its urban environment. Depending on the nature of the structure, the peak frequency is split, producing a significant beat on the displacement time history at the building top or shifted from the resonance frequency value corresponding to the standalone structure. In our case, Figure 6 shows that the same phenomenon is observed, leading to less severe vibrations in the structure located at the middle of the cluster (MB).

For $X$-direction and a southerly source, Figure 6 shows that the three towers have the same transfer function at the resonance mode $(0.4 \mathrm{~Hz})$. The numerical amplitude of the first two modes is comparable, which means that the second mode ( $2 \mathrm{~Hz}$ ) contributes significantly to the total motion of the structures in case of input seismic ground motion with energy centered at $2 \mathrm{~Hz}$, as observed at the OGSR accelerometric station. Conversely, at the frequency with the strongest coupling with the incident motion, that is, $2 \mathrm{~Hz}$, corresponding to the second mode of each structure, we find that the VE and BD towers, at the ends of the cluster, behave differently from MB. There is a small shift in the resonance frequency at constant amplitude, which may come from their position in the cluster (rather than the SSI effects assumed the same for the numerical modeling) as shown by Kitada et al. (1999). However, what is significant is the response of MB at this mode, characterized by the splitting of the frequency around the reference value (stand-alone building), and significantly reducing its amplitude. This signature partly explains the decrease in amplitude of the displacement (Fig. 5) observed for MB in the case of a source located toward the south. This result is similar to findings reported by microseismic surveys in the three towers.

At high frequency, the MB tower is characterized by a higher peak amplitude at the frequency corresponding to the third mode ( $5 \mathrm{~Hz}$ ). At the experimental mode shape (Fig. 2c), this mode is at its maximum on floors 5 and 20, which is also partly reported by the microseismic surveys, especially for MB and partially for VE and BD. Obviously, as supported by Mak and Schorlemmer (2016), the quality of the investigations used for microseismic intensities relies heavily on the completeness of answers, and their direct interpretation with respect to the numerical simulation is complex. For example, the number of answers between the sixth and fourteenth floors of the MB tower (center of the cluster) is quite small, and that may influence their interpretation through the vibration indicator or may correspond to the position of the lowest vibration not felt by inhabitants. However, numerical simulations confirmed that the three towers do not react in the same manner, depending upon their position in the cluster. In $Y$-direction (north-south), the fundamental mode of the three towers is unchanged, around $0.68 \mathrm{~Hz}$, that is, less than the modeled target frequency $(0.75 \mathrm{~Hz})$ because of SSI. The second mode differs slightly less for MB $(2.9 \mathrm{~Hz})$ than for VE and $\mathrm{BD}(3.1 \mathrm{~Hz})$ around the numerical target frequency $2.65 \mathrm{~Hz}$. There is a slight frequency increase for mode 2 , which may be due to the cluster effect. It is interesting to 

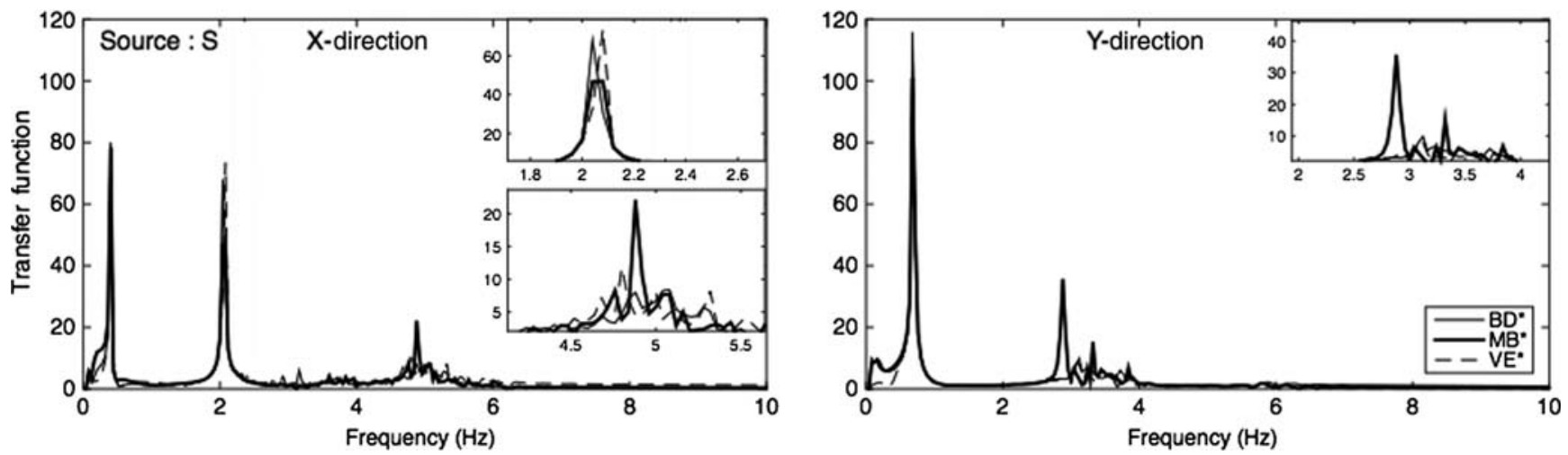

Figure 6. Transfer function in the $X$ (left) and $Y$ (right) directions for the three numerical clustered towers (noted *), based on the south source.

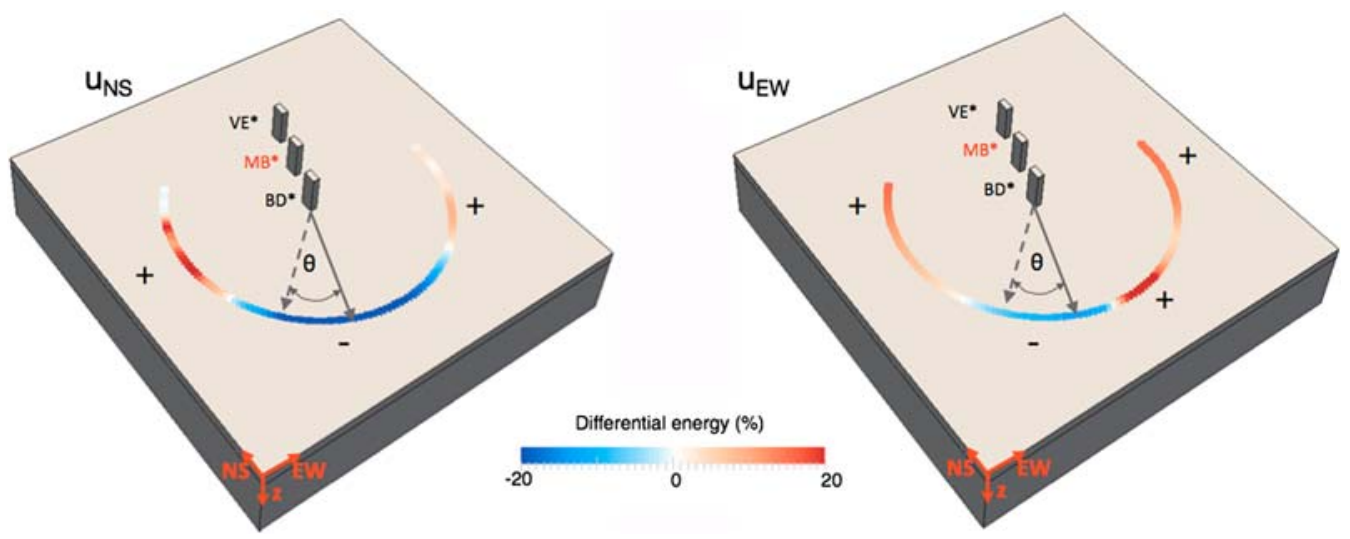

Figure 7. Variation of the differential energy of the MB* tower between the stand-alone and cluster models, recorded in the north-south (left) and east-west (right) directions and for different values of the azimuth angle $(\theta) .+$ and - indicate the positive and negative differential energy. The color version of this figure is available only in the electronic edition.

observe the same phenomenon in Figure 2b on Fourier spectra using ambient vibrations recorded at the top: the second mode in the north-south direction ( $Y$-direction) of MB is more flexible compared with those of $\mathrm{VE}$ and $\mathrm{BD}$, which are identical (labels 3 and 4).

It seems clear that the response of the three towers completely depends on the position of the source (Fig. 5). For this reason, Figure 7 shows the difference in response for the MB tower between the stand-alone and cluster models, as a function of the source azimuth. We ran several simulations with the same source located at the same distance from BD, but at a different angle of incidence $\vartheta$ with respect to the building cluster (Fig. 7). This difference is calculated as the sum of the motion energy differences on each floor in the $X$ and $Y$ directions, that is

$$
\Delta d=100 \frac{\sum_{i=1}^{N} \sum_{j=1}^{t}[T 3(i, j)-T 1(i, j)]}{\sum_{i=1}^{N} \sum_{j=1}^{t}[T 1(i, j)]},
$$

in which $\Delta d$ is the energy difference for directions $X$ or $Y, N$ is the number of floors, $t$ is the number of simulation time steps, and $T 3$ and $T 1$ are the absolute values of the Fourier transforms computed along the building height for the cluster and stand-alone models, respectively.

The $\Delta d$ value varies considerably depending on the configuration. For a south azimuth, the vibration energy in MB is attenuated in the two main directions of the tower. This changes for small variation in $\vartheta$, with quick transition from attenuation to amplification due to the cluster. It is interesting to note that $\Delta d$ does not have the same trend in the $X$ and $Y$ directions with the $X$ direction (east-west) showing the largest contrast. $\Delta d$ is nonzero in most of the cases, and it may reach values up to $20 \%$.

Having valued the microseismic observations with these numerical results, two key points remain to discuss. The first leads us to reconsider the behavior of a structure in its urban environment. Although the seismic ground motion recorded during the 2014 earthquake was moderate in Grenoble, the results of the simulation must be confirmed by integrating a nonlinear process to account for soil degradation and damage to structures caused by strong motion. However, what is observed in the elastic domain may impact the plastic domain, such as the link between the engineering demand parameter 
(e.g., structural drift) and the intensity measurement (e.g., peak ground motion); these relationships are involved in performance-based seismic design (Priestley, 2000). The energy difference between the stand-alone and cluster models can reach $20 \%$, depending on the azimuth, amplifying or attenuating the motion of the clustered buildings.

The second point may have a significant impact on the estimation of macroseismic intensity based on the people's testimonies ("Did You Feel It?"). It is well known that perceptions differ depending on the person's position in the building (Lesueur et al., 2013), and this information is used for macroseismic intensity surveys. However, even in nearby buildings, testimonials can also be very different. This leads us to consider another source of uncertainty in the interpretation of the "Did You Feel It?" reports, at least for these lowto-moderate intensity levels.

This example deals only with three buildings, but it is reasonable to imagine that overall coupling at the urban scale may have a complex response that can be characterized as a regional-size geophysical metamaterial, where a cluster of subwavelength resonators (i.e., buildings) gives rise to a new type of wave propagation physics. Metamaterials are artificial objects, engineered to have properties that have not yet been found in nature and in our case that allow full control of the wave propagation in designated frequency ranges. In the future, it might be possible to define an urban metamaterial based on the urbanization scheme to produce beneficial effects on the response of structures and seismic casualties.

\section{Data and Resources}

The accelerometric data used in this article are provided by the French Accelerometric Network (RAPRESIF), RESIF-RAP French Accelerometric Network. RESIF - Réseau Sismologique et géodésique Français. Seismic Network. doi: 10.15778/RESIF.RA, http://data.datacite.org/ 10.15778/RESIF.RA (last accessed February 2016). RAP is a member of the RESIF network, a national Research Infrastructure recognized as such by the French Ministry of higher education and research. RESIF is additionally supported by a public grant overseen by the French national research agency (ANR) as part of the "Investissements d'Avenir" program (reference: ANR-11-EQPX-0040) and the French Ministry of ecology, sustainable development and energy. We used the iconographic representation originally proposed by the French Office for Seismology (BCSF) of Strasbourg University and shown on the SismoCom mobile tool (http://www. franceseisme.fr/SMC/SMCinfo/SMCinfo.html, last accessed February 2016). The model is discretized with hexahedra using the CUBIT software package (https://cubit.sandia.gov, last accessed February 2016).

\section{Acknowledgments}

This study was sponsored by the Urban Seismology project at the Institute of Earth Science ISTerre of the University of Grenoble-Alpes and by a grant from Labex OSUG@2020 (Investissements d'avenir, ANR10-LABX56). Andrea Colombi is supported by a Marie Skłodowska-Curie fellowship.

\section{References}

Atkinson, G. M., and D. J. Wald (2007). "Did You Feel It?" intensity data: A surprisingly good measure of earthquake ground motion, Seismol. Res. Lett. 78, no. 3, 362-368.

Bard, P. Y., J. L. Chazelas, P. Guéguen, M. Kham, and J.F. Semblat (2008). Site-city interaction, in Assessing and Managing Earthquake Risk, Springer, The Netherlands, 91-114.

Brincker, R., L. Zhang, and P. Andersen (2001). Modal identification of output-only systems using frequency domain decomposition, Smart Materials Struct. 10, no. 3, 441.

Brûlé, S., E. H. Javelaud, S. Enoch, and S. Guenneau (2014). Experiments on seismic metamaterials: Molding surface waves, Phys. Rev. Lett. 112, no. $13,133,901$.

Clayton, R. W., and R. A. Wiggins (1976). Source shape estimation and deconvolution of teleseismic bodywaves, Geophys. J. Int. 47, no. 1, 151-177.

Clough, R. W., and J. Penzien (2003). Dynamics of Structures, Second Ed., McGraw-Hill, New York, New York.

Colombi, A., P. Roux, S. Guenneau, P. Guéguen, and R.V. Craster (2016). Forests as a natural seismic metamaterial: Rayleigh wave bandgaps induced by local resonances, Sci. Rep. 6, 19,238.

Colombi, A., P. Roux, and M. Rupin (2014). Sub-wavelength energy trapping of elastic waves in a metamaterial, J. Acoust. Soc. Am. 136, no. 2 , EL192-EL198.

Cornou, C., and P. Y. Bard (2003). Site-to-bedrock over 1D transfer function ratio: An indicator of the proportion of edge-generated surface waves? Geophys. Res. Lett. 30, no. 9, 1443.

Cornou, C., P. Guéguen, P. Y. Bard, and E. Haghshenas (2004). Ambient noise energy bursts observation and modeling: Trapping of harmonic structure-soil induced-waves in a topmost sedimentary layer, J. Seismol. 8, 507-524.

Courboulex, F., B. Delouis, A. Dujardin, A. Deschamps, E. Bertrand, M. Causse, C. Maron, C. Sira, and G. Cultrera (2014). The two events of Barcelonnette (French Alps), $2012\left(M_{\mathrm{w}} 4.1\right)$ and $2014\left(M_{\mathrm{w}} 4.9\right)$ : The role of directivity on ground motions, macroseismic intensities and site effects, Second European conference on Earthquake Engineering and Seismology, Istanbul, Turkey, 25-29 August 2014.

Courboulex, F., A. Dujardin, M. Vallée, B. Delouis, C. Sira, A. Deschamps, L. Honoré, and F. Thouvenot (2013). High-frequency directivity effect for an $M_{\mathrm{w}} 4.1$ earthquake, widely felt by the population in southeastern France, Bull. Seismol. Soc. Am. 103, no. 6, 3347-3353.

Favela, J., T. H. Heaton, and T. Tanimoto (2002). Far-field energy radiation from a building under harmonic excitation, AGU Fall Meeting Abstracts, A1169, http://adsabs.harvard.edu/abs/2002AGUFM.S12A1169F (last accessed September 2016).

Fichtner, A., B. L. Kennett, H. Igel, and H. P. Bunge (2009). Full seismic waveform tomography for upper-mantle structure in the Australasian region using adjoint methods, Geophys. J. Int. 179, no. 3, 1703-1725.

Grünthal, G. (2011). Earthquakes intensity, Encyclopedia of Solid Earth Geophysics, 237-242.

Guéguen, P., P. Y. Bard, and F. J. Chávez-García (2002). Site-City seismic interaction in Mexico City-like environments: An analytical study, Bull. Seismol. Soc. Am. 92, no. 2, 794-811.

Guéguen, P., P. Y. Bard, and C. S. Oliveira (2000). Experimental and numerical analysis of soil motions caused by free vibrations of a building model, Bull. Seismol. Soc. Am. 90, no. 6, 1464-1479.

Guéguen, P., C. Cornou, S. Garambois, and J. Banton (2007). On the limitation of the $\mathrm{H} / \mathrm{V}$ spectral ratio using seismic noise as an exploration tool: Application to the Grenoble valley (France), a small apex ratio basin, Pure Appl. Geophys. 164, no. 1, 115-134.

Isbiliroglu, Y., R. Taborda, and J. Bielak (2015). Coupled soil-structure interaction effects of building clusters during earthquakes, Earthq. Spectra 31, no. 1, 463-500. 
Jennings, P. C. (1970). Distant motions from a building vibration test, Bull. Seismol. Soc. Am. 60, no. 6, 2037-2043.

Kanamori, H., J. Mori, D. L. Anderson, and T. H. Heaton (1991). Seismic excitation by the space shuttle Columbia, Nature 349, $781-782$.

Kausel, E. (2010) Early history of soil-structure interaction, Soil Dynam. Earthq. Eng. 30, 822-832.

Kham, M., J. F. Semblat, P. Y. Bard, and P. Dangla (2006). Seismic site-city interaction: Main governing phenomena through simplified numerical models, Bull. Seismol. Soc. Am. 96, no. 5, 1934-1951.

Kim, W.-Y., L. R. Sykes, J. H. Armitage, J. K. Xie, K. H. Jacob, P. G. Richards, M. West, F. Waldhauser, J. Armbuster, L. Seeber, W. X. $\mathrm{Du}$, and A. Lerner-Lam (2001). Seismic waves generated by aircraft impacts and building collapses at World Trade Center, New York City, Eos Trans. AGU 82, no. 47, 565-571.

Kitada, Y., M. Kinoshita, M. Iguchi, and N. Fukuwa (1999). Soil-structure interaction effect on an Npp reactor building. Activities of Nupec: Achievements and the current status, M. Celebi and I. Okawa (Editors), Proc. UJNR workshop on Soil-Structure Interaction, Menlo Park, California, 22-23 September, paper no. 18.

Laurenzano, G., E. Priolo, M. R. Gallipoli, M. Mucciarelli, and F. C. Ponzo (2010). Effect of vibrating buildings on free-field motion and on adjacent structures: The Bonefro (Italy) case history, Bull. Seismol. Soc. Am. 100, no. 2, 802-818.

Lebrun, B., D. Hatzfeld, and P.-Y. Bard (2001). A site effect study in urban area: Experimental results in Grenoble (France), Pure Appl. Geophys. 158, 2543-2557.

Lesueur, C., M. Cara, O. Scotti, A. Schlupp, and C. Sira (2013). Linking ground motion measurements and macroseismic observations in France: A case study based on accelerometric and macroseismic databases, J. Seismol. 17, no. 2, 313-333.

Mak, S., and D. Schorlemmer (2016). What makes people respond to "Did You Feel It?", Seismol. Res. Lett. 87, no. 1, 119-131.

Michel, C., P. Guéguen, S. El Arem, J. Mazars, and P. Kotronis (2010). Full scale dynamic response of a RC building under weak seismic motions using earthquake recordings, ambient vibrations and modelling, Earthq. Eng. Struct. Dynam. 39, 419-441.

Mikael, A., P. Guéguen, P. Y. Bard, P. Roux, and M. Langlais (2013). The analysis of long-term frequency and damping wandering in buildings using the Random Decrement Technique, Bull. Seismol. Soc. Am. 103, no. 1, 236-246.

Nicoletti, O. (2014). Seismic cloaks, Nat. Materials 13, no. 5, 428-428.

Padovani, E., E. Priolo, and G. Seriani (1994). Low and high order finite element method: Experience in seismic modeling, J. Comput. Acoust. 2, no. 04, 371-422.

Péquegnat, C., P. Guéguen, D. Hatzfeld, and M. Langlais (2008). The French accelerometric network (RAP) and national data centre (RAP-NDC), Seismol. Res. Lett. 79, no. 1, 79-89.

Peter, D., D. Komatitsch, Y. Luo, R. Martin, N. Le Goff, E. Casarotti, P. Le Loher, F. Magnoni, Q. Liu, C. Blitz, T. Nissen-Meyer, P. Basini, and J. Tromp (2011). Forward and adjoint simulations of seismic wave propagation on fully unstructured hexahedral meshes, Geophys. J. Int. 186, no. 2, 721-739.

Priestley, M. J. N. (2000). Performance based seismic design, Bull. New Zeal. Soc. Earthq. Eng. 33, no. 3, 325-346.

Sbarra, P., P. Tosi, and V. De Rubeis (2010). Web-based macroseismic survey in Italy: Method validation and results, Nat. Hazards 54, no. 2, 563-581.

Sezawa, K., and K. Kanai (1935). Decay in seismic vibration of a simple or tall building structure by dissipation of their energy into the ground, Bull. Earthq. Res. Inst. XIII, no. 3, 681-697.

Singh, S. K., E. A. Mena, and R. Castro (1988). Some aspects of source characteristics of the 19 September 1985 Michoacan earthquake and ground motion amplification in and near Mexico City from strong motion data, Bull. Seismol. Soc. Am. 78, no. 2, 451-477.

Sira, C., A. Schlupp, and M. Schaming (2010). Sismocom: Application mobile pour témoigner et être informé sur les séismes, Mappemonde 99, no. 3, http://mappemonde.mgm.fr/num27/fig10/fig10304.html (last accessed October 2015).

Stewart, J. P., and G. L. Fenves (1998). System identification for evaluation soil-structure interaction effects in buildings from strong motion recordings, Earthq. Eng. Struct. Dynam. 27, 869-885.

Valla, M., P. Guéguen, B. Augère, D. Goular, and M. Perrault (2014). Remote modal study of reinforced concrete buildings using a multipath Lidar vibrometer, J. Struct. Eng. 141, no. 1, D4014005, doi: 10.1061/ (ASCE)ST.1943-541X.0001087.

Wald, D. J., V. Quitoriano, C. B. Worden, M. Hopper, and J. W. Dewey (2012). USGS "Did you feel it?" internet-based macroseismic intensity maps, Ann. Geophys. 54, no. 6, doi: 10.4401/ag-5354.

Wirgin, A., and P. Y. Bard (1996). Effects of buildings on the duration and amplitude of ground motion in Mexico City, Bull. Seismol. Soc. Am. 86, no. 3, 914-920.

Wong, H. L., and M. D. Trifunac (1975). Two-dimensional, antiplane, building-soil-building interaction for two or more buildings and for incident plane SH waves, Bull. Seismol. Soc. Am. 65, no. 6, 1863-1885.

ISTerre, CNRS/IFSTTAR, Université Grenoble-Alpes CS40700, 38058 Grenoble

France

Philippe.gueguen@ujf-grenoble.fr

(P.G.)

Department of Mathematics

Imperial College London

South Kensigton Campus

London SW7 2AZ, UK

(A.C.)

Manuscript received 24 February 2016; Published Online 27 September 2016 